\title{
Golden Aging: Prospects for Healthy, Active, and Prosperous Aging in Europe and Central Asia
}

MAURIZIO BUSSOLO, JOHANNES KOETTL and EMILY SINNOTT The World Bank, Washington DC, 2015, pp. 329

Book review by ŠIME SMOLIĆ*

https://doi.org/10.3326/pse.42.3.6

\footnotetext{
* Received: July 16, 2018

Accepted: July 17, 2018
}

Šime SMOLIĆ, Ph.D.

Faculty of Economics and Business, Trg J. F. Kennedyja 6, 10000 Zagreb, Croatia 
In the next few decades, we will witness an intensive process of ageing in Europe, a phenomenon that has been mainly supported by lower fertility rates. Our societies will have to face many challenges and opportunities created by demographic drivers and the economic consequences of a demographic shift. The authors of Golden Aging: Prospects for Healthy, Active, and Prosperous Aging in Europe and Central Asia analyse in depth both the main challenges of and the opportunities provided by demographic trends countries of Europe and Central Asia (ECA), a region with the oldest populations in the world. In this report, 27 countries of ECA are divided into the Western Balkans, Eastern Partnership and Russian Federation, Central Europe and Youth Countries (Central Asia and Turkey). They also say that this is not the first time that demographic trends raised concerns about social welfare, productivity, savings and so on. A very similar if quite opposite situation was present during the 1970s when high fertility rates were blamed for raising concerns about growth welfare and fiscal sustainability. The ideal situation for many ageing societies is just to fit in with the idea of the "Golden Age", defined in Greek mythology as a time of peace, harmony, stability, and prosperity when humans lived to a very old age. However, transition to more balanced demographic profiles, with fewer young people and higher share of elderly, for some countries could be a difficult or even unattainable process.

In the Introduction (Overview), the authors compare the demographic situation of ECA countries and that of the rest of the world. They use the average number of years of life remaining or the median age as more precise indicators to describe ageing populations. Fertility decline is described as the most important driver of ageing in the countries of ECA. In addition, in these countries they observe a modest increase in life expectancy if in some of them an increase in mortality rates in older age groups. Thus, more changes in mortality are expected (and needed) in some countries from this region especially in the field of health care efficiency, and the changes in health risk behaviours. When it comes to the economic consequences, they use the illustrative example of the ageing population of Japan, and do not find ageing itself as the most important contributor to the economic slowdown in this country. Indeed, they continue to state that most ECA countries could experience positive effects from ageing in the macroeconomic perspective. They conclude this part by questioning what impact ageing could have on labour force participation, productivity, capital and economic inequality. To reach the golden demographic age, countries of ECA region should implement wide-range reforms especially in the area of health care, pension system, education, and labour market.

Apart from the Introduction, the book consists of three parts divided into seven chapters. In Part I, demographic transition in Europe and Central Asia is analysed in two chapters: "The drivers of aging in Europe and Central Asia", and "Improving health outcomes in the transition to the Golden Age". The first chapter presents the model of demographic transition; explores the effects of declining fertility on ageing and population growth, and tries to answer the reason for the decline in fertility. Examples presented are revealing the extent of demographic changes 
in ECA countries. When comparing total fertility rate decline in France and Albania they say that the "...the shift from an average fertility rate of over five children per woman to below the population replacement rate took two centuries in France but only 34 years in Albania" (page 42). An interesting discussion tackled the effects of economic crisis of 2008 on fertility, and another one answered the question of why fertility is higher in France than in Germany. As for life expectancy and mortality, the ECA region has recorded s smaller improvement in life expectancy than all other regions of the World. Since 1960s, life expectancy in this region increased by 10 years only, while in Latin America people gained 18 and in East Asia and Pacific more than 27 years. Gains in male life expectancy were extremely limited in Eastern European countries (Czech Republic, Hungary, Moldova, Poland, Romania, Russia, Slovakia), and mortality in middle age (mid-40s to early 60s) has hardly improved in the ECA region. In general, it is concluded that women live longer than men in ECA, and people in richer socioeconomic groups also live longer.

The second chapter discusses the high incidence of disease and disability in the ECA region, and the challenges that need to be overcome to achieve a healthy aging population, and the implications of demographic developments for caregivers. Several striking conclusions stem from this chapter. For example, in many countries of the ECA region a man in 2009 was not in better health than a man in 1959 (page 79). Another is the high burden for elderly caregivers due to high levels of disease and disability in this region. Authors point to the limited availability of formal services in the region as the main reason why the bulk of eldercare, as well as childcare, is provided often by female family members (page 81). In addition, there is a note on "sandwich generations", i.e. people who are expected to provide care to multiple generations at the same time, normally to their parents, children or grandchildren. Earlier research suggest that "married women who are out of the labour force, and better-educated women earning greater incomes, are at the highest risk of becoming trapped in a care sandwich". Cardiovascular diseases and health risk behaviours are found to be the most important factors affecting the health outcome gap between ECA region and Western Europe countries. Longer and healthier lives for people in ECA region are possible if they succeed in solving the problem of the excess of morbidity and mortality that has been driven by cardiovascular and other noncommunicable diseases (page 92).

"The Economic Consequences of Aging" is the title of Part II, and three chapters are employed to discuss the most important consequences of ageing. Chapter 3 mainly focuses on the macroeconomic impact of population ageing, in particular how ageing will influence income and growth, labour participation and savings, and government balances. Authors use the overlapping generations (OLG) model to explore the economic impact of ageing through two simulations - declines in fertility and increases in longevity, the two major drivers of demographic change. Their conclusions about GDP per capita growth are positive in both simulations, e.g. GDP per capita will increase by 6 percent in the next forty years in a simula- 
tion with a decline in fertility (page 113). They also explain the macroeconomic mechanisms behind this increase of GDP per capita, and conclude that "as people live longer they also work until older ages. And with slower population growth, it can become easier to increase capital-to-labour ratios and boost worker productivity". Increased longevity they say could change decisions on savings and labour participation by people who anticipate a longer time in retirement being likely to save more during their life. Authors present many valuable analyses based on the EU Labour Force Survey (LFS), The Survey of Health, Ageing and Retirement in Europe (SHARE), International Labour Organization (ILO), and ECA countries fiscal databases.

Chapter 4 analyses the effects of ageing on productivity due to changes in the age structure of the workforce. An important observation here is the adjustment for educational differences when making cross-country comparisons of younger and older workers today. Adjustment should be made for the occupational distribution of the employed population. The finding is that “...younger generations entering the labour markets of Europe and Central Asia (and over the past 20 years) have (and have had) much higher levels of educational attainment than the generations exiting the labour market because of age" (page 170). Moreover (e.g. looking at scores from the PISA International Database), the quality of the education has risen in recent years, and the skills of labour market entrants too. The skills of older workers are not declining due to the ageing process, while some inevitable decline in cognitive functioning is compensated with better functioning in other functions (page 178). There is evidence that companies in ageing countries have responded by shifting their export patterns as they become more productive in sectors relying more on skills that improve with age (page 185).

In the Chapter 5, the authors question whether inequality and poverty increase in ageing societies. At the very beginning, they say that answering these questions would be a complex task. Nevertheless, we can draw some conclusions about poverty and inequality in ECA region: elderly are not the poorest group in ECA region, nor does ageing necessarily lead to higher poverty rates. Pensions and transfers have an important role in addressing the financial situation of the elderly. When looking at the trends in poverty and inequality in the region, authors observe two distinct phases: the first covers the decade from the mid-1980s to the mid-1990s; the second extends from the mid-1990s to the present. During the first period, poverty and inequality rose sharply as countries transitioned to market economies. In the next fifteen years, absolute poverty dropped to less than 10 percent on average across countries. Inequality stabilized after the transition and even decreased in some cases (page 218). When it comes to poverty and ageing, the higher share of elderly does not necessarily imply higher overall poverty rates (page 220).

Part III covers the policies related to ageing societies, both policies already in the process of implementation and those policy areas that deserve much more atten- 
tion in stabilizing demographic structure and dealing with the negative economic consequences of demographic ageing. In Chapter 6, demographic ageing is discussed in the context of the baby-boomers who hold significant electoral power and do not support (needed) radical reforms. They prefer the status quo, and while some reforms, e.g. education or health care systems could pass without major opposition, any attempt at a reform of the pension system could be a challenge for many governments. In the situation of ageing of voters, authors analyse the emergence of pensioners' parties in Europe, and their relative success in influencing important decisions as compared to the percentage of votes gained at the parliamentary elections. A big challenge for ageing countries can be observed in the competition between pensions and education for spending (page 269). The last part of this chapter explains the attitudes toward migration in ageing societies. While attitudes toward immigration could become positive as the whole society ages, this does not mean that they will become positive in ECA countries over time. One very good predictor of anti-immigrant sentiment is labour market performance, i.e. as unemployment increases, positive attitudes towards immigrants tend to decrease (page 276).

Chapter 7 discusses several key policy areas relevant to achieving "Golden Ageing" in Europe and Central Asia. Here we can find policies supporting a rebound in fertility to near replacement rates, improved healthy life expectancy, and increases in net immigration rates (page 282). Balancing family and work life, especially for women, would help bring fertility closer to the replacement rate. Provision of formal childcare from an early age is the most effective means for achieving this goal. Another field for action is long-term care including care for the elderly that should shift from informal caregiving to formal, more extensive and sustainable approaches.

The authors of this report and their contributors have invested a very great effort in analysing the most striking topic of modern societies - population ageing. At the very beginning of this report, there is a crucial graph indicating how the demographic drivers and economic consequences of aging create both challenges and opportunities. The report reveals not only the disadvantages of but also the many opportunities arising from demographic ageing in ECA countries. "Golden Ageing" is within reach in ECA countries. However, it will require coordinated actions among different actors, including the government, the private sector, and societies, and across many areas, ranging from labour markets to health care to education and pensions. 